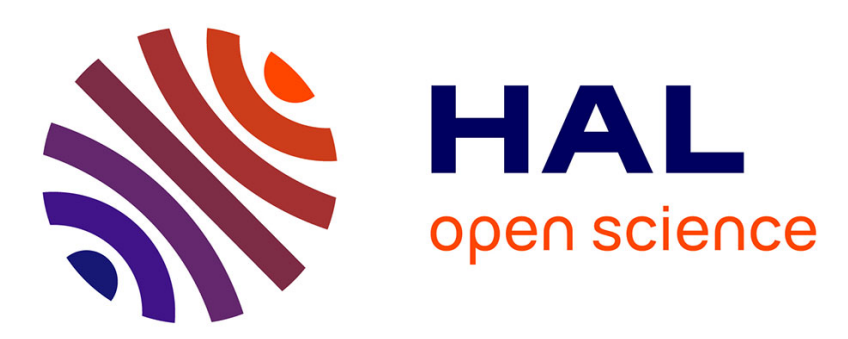

\title{
Getting inspiration or creating inspiration? The role of knowledge structures in idea generation
}

\author{
Juliette Brun, Pascal Le Masson, Benoit Weil
}

\section{To cite this version:}

Juliette Brun, Pascal Le Masson, Benoit Weil. Getting inspiration or creating inspiration? The role of knowledge structures in idea generation. Design 2018 - International Design Conference, May 2018, Dubrovnik, Croatia. 10.21278/idc.2018.0196 . hal-01828023

\section{HAL Id: hal-01828023 \\ https://hal.science/hal-01828023}

Submitted on 2 Jul 2018

HAL is a multi-disciplinary open access archive for the deposit and dissemination of scientific research documents, whether they are published or not. The documents may come from teaching and research institutions in France or abroad, or from public or private research centers.
L'archive ouverte pluridisciplinaire HAL, est destinée au dépôt et à la diffusion de documents scientifiques de niveau recherche, publiés ou non, émanant des établissements d'enseignement et de recherche français ou étrangers, des laboratoires publics ou privés. 
INTERNATIONAL DESIGN CONFERENCE - DESIGN 2018

https://doi.org/10.21278/idc.2018.0196

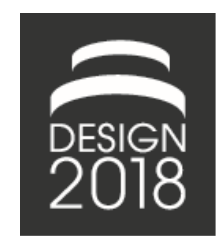

\title{
GETTING INSPIRATION OR CREATING INSPIRATION? THE ROLE OF KNOWLEDGE STRUCTURES IN IDEA GENERATION
}

\author{
J. Brun, P. Le Masson and B. Weil
}

\begin{abstract}
Every designer - experienced or not - aspires to live Aha! moments, but how to favor these moments, where original ideas emerge, is not always obvious. While design methods often focus on the concept space, this article highlights the role of knowledge structuration in idea generation. By analyzing two cases of idea generation sessions with C-K theory, we show that generativity relies on the designers' ability to reorganize their own knowledge basis and thus create new design rules. "Incompatible knowledge" especially helps fostering such restructuration, and therefore, provoking inspiration.
\end{abstract}

Keywords: idea generation, $C-K$ design theory, knowledge structuration, design creativity, non-verbal tools

\section{Introduction}

In his book "The Diary of a Nose", the French perfumer Jean-Claude Ellena explains that the design of a fragrance is not the result of an orderly and successive arrangement of scents (Ellena, 2012). Indeed, the perfume components are not to be read in a continuous order, as words or music notes could be: it is a question of composing the components and making them interact together. After opening the bottle of perfume, the aromatic essences are all simultaneously perceptible and cannot express their meaning independently of one another: the links between fragrances therefore play an important part in the design of a perfume and Ellena explains that such structuration of his own knowledge is precisely what fosters the creation of original and innovative perfumes.

If the knowledge structure of a perfume designer may strongly influence the creation of a new product, one may wonder how existing links between knowledge, as well as recently established links, may impact the result of a design process. The impact of knowledge structuration as already been largely explored by the literature on rule-based design. Specific rules have been proposed in order to optimize the design of products, and they often prove to be associated to a dedicated structuration of knowledge. One of the most prominent examples is probably the Suh Axiomatic (Suh, 1990, 2001), which requires modeling an object by distinguishing its functions and its components. Based on this specific structuration of knowledge, Suh explains that only a certain category of links between knowledge allows optimizing the product's design. Structuration of knowledge has proved to be particularly effective when it come to design a product whose identity is well-known. However, knowledge structures associated to rule-based design have also shown limits when it comes to renew the identity of products, i.e. to create completely new objects: for instance, the Axiomatic method does not explain how to create both new components and new functions. Such activity corresponds to an innovative design process and involves the creation of "unknown objects" (Hatchuel and Weil, 2009). In innovative design, the effect of the knowledge structure on the nature of design still constitutes a new research question: in order to explore the unknown and create completely 
new products, innovative design has indeed often encouraged a search for original knowledge (Kelley and Littman, 2001) and emancipation from rigid knowledge structures (Hatchuel and Weil, 2009). However, if it promotes knowledge expansion, innovative design theory also considers all possible knowledge structures without promoting a particular type of links between knowledge (e.g. function/component modeling), or in other words, a specific structuration of knowledge. In this way, we may wonder if some knowledge structures are able to foster design originality and new concept generation: are some knowledge structures more generative than others? And could new knowledge introduction impact this structure, eventually modify it, and thus increase or decrease the generativity of the design process?

Our research project therefore aims to understand the role of knowledge structuration in idea generation. In order to explore the impact of knowledge structuration on generativity, we rely on two case studies involving idea generation: the first case study corresponds to an idea generation exercise led by an architect to generate original concepts. The second case study shows an idea generation session led at the Renault automotive company, whose aim was to imagine new charging solutions for Electric Vehicles. Moreover, we choose to study idea generation sessions that involved non-verbal devices (drawings for the architect, and pictures at Renault) because we assumed that they would involve particularly flexible knowledge structures, which could help highlighting interesting phenomena.

\section{Literature review}

\subsection{The impact of knowledge structures in design}

The importance of knowledge structures has already been highlighted by literature in rule-based design: when it comes to design a product with a stable identity, distinguishing useful links between knowledge may help optimizing the design process. For example, The General Design Theory of Yoshikawa (1981) relies on a rigorous mapping and structuration of the knowledge space (Reich, 1995; Hatchuel and Weil, 2009). Rearranging links between knowledge may indeed help optimizing the design of a new product. In rule-based design, a classic structuration of the knowledge space associated to a product consists in distinguishing functions (or functional requirements FR) from components (or design parameters DP) (Ulrich, 1995). In Suh Axiomatic, designing a product consists in building a certain series of links between FR and DP, i.e. associating the product's objectives to the components that will fulfill them. Moreover, the design will be optimal if one FR is associated to one and only one DP, and vice versa. More generally, a rigorous structuration of knowledge is particularly valued in engineering design (Le Masson et al., 2017). Indeed, identifying and fostering deterministic between knowledge allows to quickly locate the source of a problem, whereas fostering modular links in the knowledge structure allows reusing the same components in different ways: for instance a car manufacturer will give preference to a door handle that can fit a wide range of car models. In this way, rule-based design often relies on knowledge structuration and recognizes its major role in design performance. But if specific knowledge structures are recommended in rule-based design, where products identities are stable, the knowledge structure is often considered as a free parameter in innovative design (Le Masson et al., 2017).

\subsection{The role of knowledge categories in innovative design}

In order to foster the generation of completely new concepts, i.e. to enhance generativity, innovative design recommends to look for expansive and original knowledge: for instance, Design Thinking encourages the acquisition of both tacit and user-centered knowledge (Kelley and Littman, 2001). Original knowledge will also allow associating surprising properties to well-known products, therefore opening new paths for a renewal of products' identity (Hatchuel and Weil, 2009). The example of a design exploration related to the concept of "social drone" allows illustrating the importance of mobilizing surprising knowledge. Such design indeed corresponds to an exploration of the unknown: what a social drone could be still remains undecidable (A drone connected to social networks? A drone beneficial for society?). The property "social" is thus a surprising property. Exploring the different definitions of the word "social", original knowledge bases could be mobilized, such as knowledge on civil security and firefighters. Whereas drones are often associated to private use, leisure activities and communication, new knowledge regarding firefighters allows generating original concepts, such a drone that could detect ignition in sparsely populated areas, and automatically alert fire brigades. 
In this example, knowledge regarding firefighters is mobilized because it allows expanding the knowledge base associated to the term "social". Such input thus appears associated to the initial problem. However, this link between the design topic and new knowledge inputs mobilized by the designer is not always obvious. Indeed, concept generation may involve knowledge that is clearly related to the design problem ("related stimuli"), as well as knowledge that appears unrelated to the design topic ("remote stimuli") (Smith, 1998). Moreover, both kinds of knowledge have to be considered and may allow increasing originality during idea generation (Smith, 1998).

However, if design theory defines an original knowledge as an element expanding already acquired knowledge (Hooge et al., 2012), the definition of what could be "related knowledge" or "unrelated knowledge" still remains unclear. Could these two types of knowledge be defined in association to the knowledge structure of the problem? Do they present the same generative effects, i.e. the same impact on idea generation?

\subsection{How the nature of knowledge impacts idea generation}

Cognitive science has already highlighted that the nature of mobilized knowledge may strongly influence the generativity of a design exploration. Indeed, the designer's knowledge basis may strongly influence his/her ability to generate new innovative concepts (Jansson and Smith, 1991; Agogué et al., 2013). A designer is systematically fixed by his own knowledge: the generation of ideas that do not correspond to familiar solutions proves to be particularly difficult. This corresponds to a cognitive effect named "fixation effect" (Jansson and Smith, 1991). In order to tackle fixation, new knowledge may be introduced. However, the nature of knowledge will play an important role. Depending on the type of knowledge, new inputs may either foster generativity or increase fixation (Smith et al., 1993; Agogué et al., 2013). It has been proven that restrictive knowledge corresponding to non-original conceptual paths will decrease the designer's generativity, whereas original knowledge inputs will help enhance the variety and the originality of the ideas produced (Agogué et al., 2013). For instance, in an experiment currently referred as the "egg task", participants are asked to imagine various and original solutions so that an egg, which will be dropped from the top of a building, does not break. $80 \%$ of ideas generated during the task belong to three types of classical solutions: slowing down the fall (e.g. with a parachute), protecting the egg (e.g. with bubble wrap) and damping the shock (e.g. with a mattress). Such percentage allows highlighting fixation (Agogué et al., 2013). More original solutions to the task may indeed be proposed such as playing on the physical properties of the egg (e.g. increasing the resistance by boiling the egg and then freezing it) or using a living device (e.g. such as a trained falcon). Moreover, if the task protocol is given to participants with an example of solution, this may either increase or decrease fixation. The example of the parachute will increase the ratio of restrictive ideas, whereas the example of the trained falcon will increase originality and foster the generation of expansive ideas.

\subsection{Investigating the impact of knowledge structures on idea generation}

If the restrictive or expansive nature of knowledge may influence idea generation in innovative design, the way the knowledge structure of the designer impacts originality remains unclear: in addition to the nature of each element of the designer's knowledge basis, the links made between elements, such has rules, paradigms or determinisms, may also play an important role and influence fixation. Indeed, recent studies studying the design process of artists have shown that the knowledge structure may foster generative effects and enhance the idea generation process. For instance, a knowledge basis avoiding both deterministic and modular links fosters the production of original concepts (Brun et al., 2016). In the same way, the relation between a new knowledge input and the knowledge structure has to be considered. Literature on the impact of examples has studied examples of solutions corresponding to both elements that are automatically mobilized by the designer when thinking of the design topics (e.g. the parachute) and elements that are not automatically mobilized (e.g. the trained falcon). But the way these new inputs impact the knowledge structure (for instance, by allowing breaking design rules and creating new paradigms), as well as the way such restructuration impact idea generation, still has to be explored. In this paper, we investigate the role of knowledge structures in innovative design, and especially, the impact of new inputs on knowledge structuration and idea generation. We studied two idea generation sessions: one session led by an experienced architect looking for new ideas, and another led in a large 
firm by a team aiming to produce new ideas for Electric Vehicle charging. In each case, the relation between new knowledge inputs and the initial knowledge structure of either the architect or the team has been explored. The following section presents how we analyzed the impact of new knowledge on knowledge structuration and idea generation. We then present our results and discuss further lines of development.

\section{Methodology}

\subsection{Research settings: Idea generation sessions mobilizing non-verbal devices}

In order to understand the impact of knowledge structures on idea generation, we chose to focus on sessions mobilizing non-verbal devices, such as drawings or pictures. Since we wanted to highlight interesting phenomena in association with knowledge structuration, we needed to select design cases that would be more likely to mobilize flexible knowledge structures, which present links that are easily modifiable, or at least, more likely to change. Regarding this flexibility, we relied on research works emphasizing the instant feedback existing between a designer and his/her non-verbal media (Schön, 1983; Goldschmidt, 2003), and the ability of these media to bring new and original knowledge to the designer, who can thus quickly modify his/her ideas (Goel, 1995; Suwa and Tversky, 1997; Goldschmidt, 2003). Therefore, we assumed that the knowledge structure of designers working with non-verbal devices might be particularly agile and more likely to present interesting variations.

We studied two idea generation sessions: the first case corresponds to an architect aiming to design a new bookcase for his own agency (Case 1), whereas the second case consists in an idea generation session led by a team of the Renault automotive company that intended to develop new charging solutions for Electric Vehicles (EV), relying on communities (Case 2).

During the first session, the architect realized a sequence of drawings to explore original solutions of bookcases. The designer wanted the bookcase to allow glass tile integration and to reflect the agency's identity. A sample of drawings is presented in Figure 1. In Case 1, we analyzed the design process of the architect retrospectively, by leading with him several in-depth interviews in order to collect propositional data. These interviews aimed at understanding the design reasoning followed by the architect while sketching, and especially the impact of knowledge on this reasoning. These interviews represented around 6 half-days of work. The analysis of the data was regularly presented to the architect, who could thus validate our analysis, add information, or suggest changes.
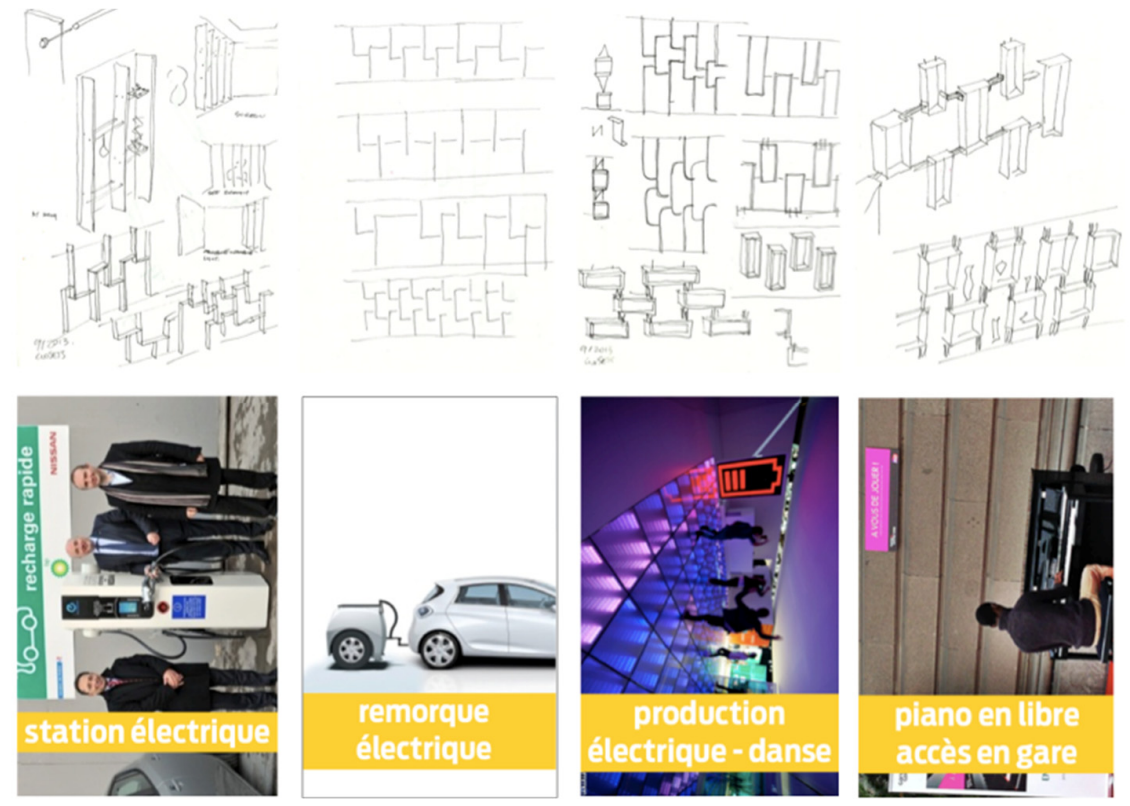

Figure 1. A sample of sketches corresponding to the bookcase exploration (Case 1) and some pictures belonging to the Renault card deck (Case 2) 
In Case 2, the Renault team wanted to find new original ways to create a larger network of charging points, which could gather both private and public charging points. Indeed, private charging points are often located in private homes and are not as accessible as public charging points. Finding original ways to provide a better access to these charging points could help improve the density of the charging point network and then improve the EV range. The team was therefore asked to generate original ideas of EV charging solutions relying on communities, on the basis of new knowledge inputs presented through a card deck. This set of cards consisted in 48 pictures, which presented different types of knowledge (see Figure 1). Each picture also included a title. An experienced designer was in charge of the meeting facilitation: he presented each picture to the team and read their titles aloud. In this second case, we collected our data during the session, by taking notes regarding the design reasoning followed by the Renault team.

In order to understand the impact of the knowledge structure on idea generation in each case, we had to identify how new knowledge brought by the non-verbal devices would influence the exploration of the designers: would they bring new ideas without modifying the existing knowledge structure? Would they change the knowledge structure? And if so, would they increase or decrease the designers' ability to generate original ideas? To understand the influence of new knowledge, we thus had to find a generic way to model the impact of new inputs on the design reasoning followed by both the architect and the Renault team.

\subsection{Modeling the impact of new knowledge introduction on idea generation with $\mathrm{C}-\mathrm{K}$ theory}

For this purpose, we relied on C-K theory, which offers a theoretical framework to model design reasoning and design moves (Hatchuel and Weil, 2009). The C-K theory distinguishes two spaces: the $\mathrm{K}$-space (or Knowledge space) and the $\mathrm{C}$-space (or Concept spaces). $\mathrm{K}$ refers to knowledge, to what is known and decidable, whereas $\mathrm{C}$ refers to ideas, to what is unknown and undecidable. According to $\mathrm{C}$ $\mathrm{K}$ theory, the design process consists in expanding both Concept and Knowledge spaces: the interplay between knowledge and concepts is precisely what allows innovative ideas to emerge (see Figure 2).

From a formal point of view, the distinction between knowledge and concepts is based on logic: knowledge corresponds to propositions with a logical status (true/false, exist/does not exist, $0 / 1$, are all examples of possible logical status), while concepts correspond to propositions without logical status. For instance, the proposition "drone" is knowledge for most people: we know that drones exist. A "social drone" however will be a concept: at the beginning of the design process, it is impossible to say if such drone exists, or what form it could take. Moreover, the Concept or Knowledge status depends on the knowledge basis of the designer: a social drone will become knowledge once aware of the existence of drones assisting firefighters.

Moreover, in C-K theory, the Concept space is an organized and structured space: links between concepts appear (they consist in partition and inclusion links). The Knowledge space however consists in isolated bases. The representation of the C-and $\mathrm{K}$-spaces is presented in Figure 2.

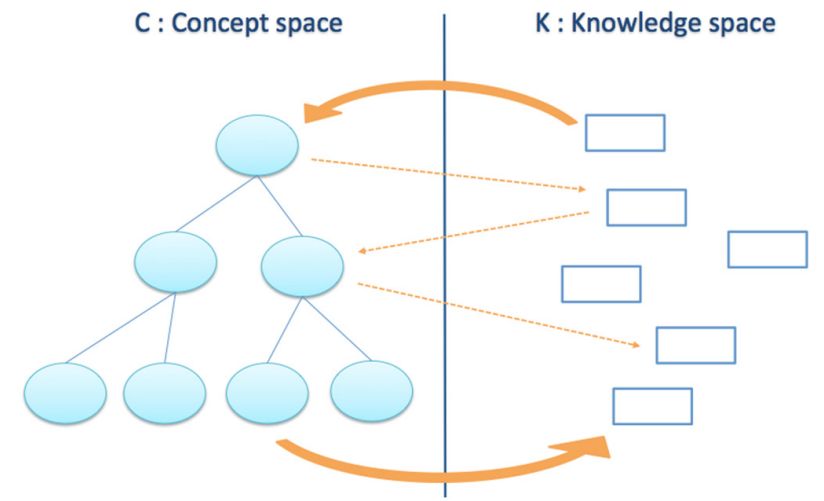

Figure 2. C-K theory: A distinction between Concepts and Knowledge

The C-K theory also distinguishes four design operations, depending on the way a designer will explore $\mathrm{C}$ and $\mathrm{K}$ : 
- K->C: this operation consists in adding or subtracting knowledge to refine the definition of concepts. It therefore allows generating alternatives in the $\mathrm{C}$-space.

- $\mathrm{C}->\mathrm{K}$ : this operation allows exploring knowledge in the $\mathrm{K}$-space in order to understand a concept $\mathrm{C}$ without logical status.

- $\mathrm{C}->\mathrm{C}$ : this operation allows creating concept alternatives by following rules of set theory (inclusion or partition operations).

- K->K: this operation corresponds to a self-expansion of the K-space. It may consist in exploring knowledge thanks to deduction, modelling, optimization, or evaluation operations.

In our study, we aimed at identifying the way new knowledge brought by the non-verbal devices was mobilized in order to generate new ideas. Since $\mathrm{K}$ and $\mathrm{C}$ are only related to verbal statements, we considered non-verbal devices as a dedicated design space called $\mathbf{D}$. This introduced four new design operators (D->K, D->C, K->D, C->D) and allowed taking into account D->K operations, which correspond to a situation where a non-verbal media brings a piece of knowledge to the designer(s) (either the architect or the Renault team). Here, K may be either knowledge that the designers already knew or new knowledge. $\mathrm{K}$ may also corresponds to knowledge already mobilized during the idea generation session when thinking about the initial topic, or to knowledge that was not previously activated. For each session, we therefore identified the occurrence of $\mathrm{D}->\mathrm{K}$ operators. Moreover, in order to understand the impact of these new inputs on the knowledge basis, we modeled the initial composition of the designers' Knowledge space for the two case studies: this initial Knowledge basis will be noted K0. It consists in a collection of knowledge bases automatically mobilized when dealing with the design topic: for instance, the initial knowledge basis K0 related to the concept of "social drones" would mobilize knowledge on drones, social media and social good.

We then had to understand how new knowledge inputs would impact $\mathrm{K} 0$ and its initial structure. This impact could consist in either simple expansion of $\mathrm{K} 0$ (the structure remains the same) or both expansion and restructuration of $\mathrm{K} 0$. We also distinguished two types of knowledge depending on the related or unrelated nature of the knowledge inputs. Knowledge that appeared unrelated to the initial knowledge structure was noted $\mathbf{K}^{*}$, whereas Knowledge that appears related to the design topic was still noted $\mathrm{K}$. A $\mathrm{K}^{*}$-element cannot be reached by a simple expansion of $\mathrm{K} 0$ : it consists in incompatible knowledge. $\mathrm{K}$-elements however can be related to a knowledge basis already present in $\mathrm{K} 0$ : they will be referred as compatible knowledge. Regarding an exploration on social drones, knowledge regarding firefighters will consist in compatible knowledge (related to the "social good" base). Knowledge regarding luxury goods will however be considered as incompatible knowledge (see Figure 3). Moreover, in the same way that the $\mathrm{C} / \mathrm{K}$ status depends on the designer's knowledge basis, the compatible/incompatible status depends on the initial structure of the designer's knowledge basis.

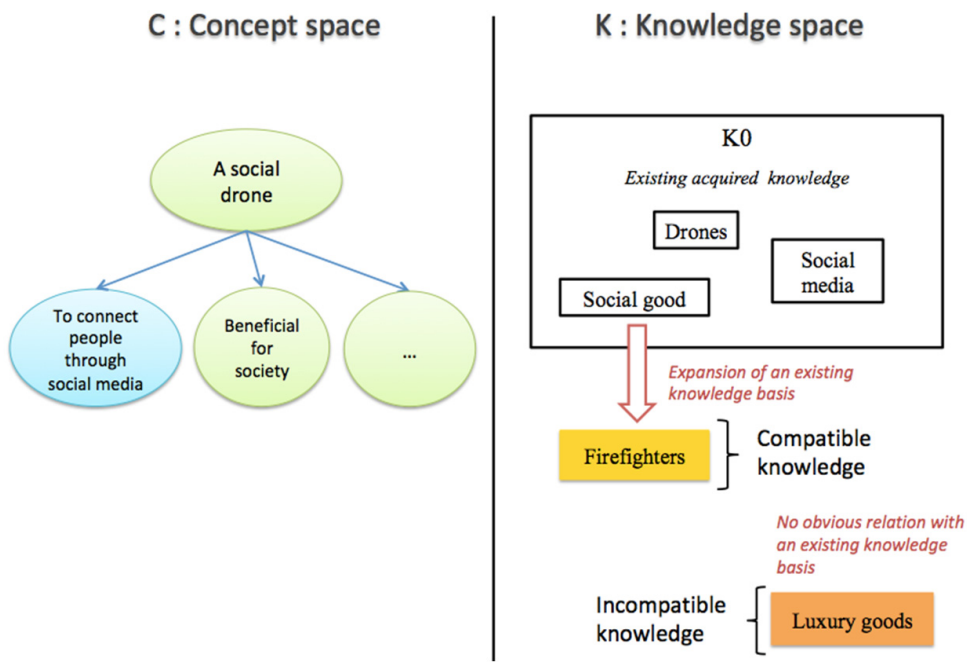

Figure 3. Example of compatible knowledge and incompatible knowledge regarding the design of social drones 
Since our research project aimed at understanding the impact of the knowledge structure on idea generation, we thus had to assess (1) the impact of the type of knowledge input on the knowledge structure (restructuration or no restructuration), (2) the impact of the type of knowledge input on idea generation and (3) the relation between knowledge restructuration and idea generation.

\section{Results}

The interactions between the architect and his sketch on the one hand, and between the team and the pictures on the other hand, were very different. Regarding the architect and his sketches (Case 1), a real dialog took place between the drawings and the designer. The sketches sometimes directly bring new concepts to the designer, and sometimes provide him with knowledge that he had already mobilized (for instance, $\mathrm{K}$ about former projects or regulation), or with knowledge that has not previously mobilized (for instance, knowledge on new forms and patterns). In return, the architect also included concepts and knowledge, which did not come from the sketches, in his drawings. Concerning the Renault team and the card deck, the pictures were only used to bring knowledge to the team members. In the same way, knowledge was either knowledge already activated or new knowledge, which could appear less or more original to the team. However, the Renault team did not modify the card deck in return. The section below shows the occurrence of the $\mathrm{D}->\mathrm{K}$ and $\mathrm{D}->\mathrm{K}^{*}$ operators in Case 1 and Case 2 . The next section explains how these knowledge inputs impacted the knowledge structure of the designers, and explores the correspondence between potential knowledge restructuration and new idea generation.

\subsection{Occurrence of $D->K$ and $D->K^{*}$ operators}

In Case 1, the architect read new original knowledge in his drawings on several occasions: this new knowledge inputs were either compatible $(\mathrm{K})$ or incompatible knowledge $\left(\mathrm{K}^{*}\right)$. For instance, the architect focused on different shapes for the bookcase pattern ("L-shape", "C-shape" or "round edges"), which are compatible knowledge. But he also read incompatible knowledge in his drawings, for instance knowledge on "cables" or "Chinese motifs". In fact, the architect's sketches dealt exclusively with the K-space: very surprisingly, only $\mathrm{D}->\mathrm{K} / \mathrm{K}^{*}$ and $\mathrm{K} / \mathrm{K}^{*}->\mathrm{D}$ operations were observed regarding the interaction between the architect and his drawings. The session led to $21 \mathrm{~K} / \mathrm{K}^{*}->\mathrm{D}$ operations and $13 \mathrm{D}$ $>\mathrm{K} / \mathrm{K}^{*}$. The latter includes $7 \mathrm{D}->\mathrm{K}$ and $6 \mathrm{D}->\mathrm{K}^{*}$ (see Table 1 ). Thus, the session did not allow to generate concepts directly from the sketches (no D->C operations), even if concept generation did occur through classic $\mathrm{K}->\mathrm{C}$ operations (new knowledge is used by the architect to generate a new concept). Moreover, the architect did not put concepts in his drawings either.

In Case 2, the Renault team was asked to use pictures in order to generate new ideas. The pictures presented both compatible $(\mathrm{K})$ and incompatible knowledge $\left(\mathrm{K}^{*}\right)$. The initial knowledge basis of the team consisted in knowledge related to EVs, EV charging systems, electricity production systems and car sharing services. The Figure 4 below presents examples of both compatible and incompatible knowledge in Case 2.

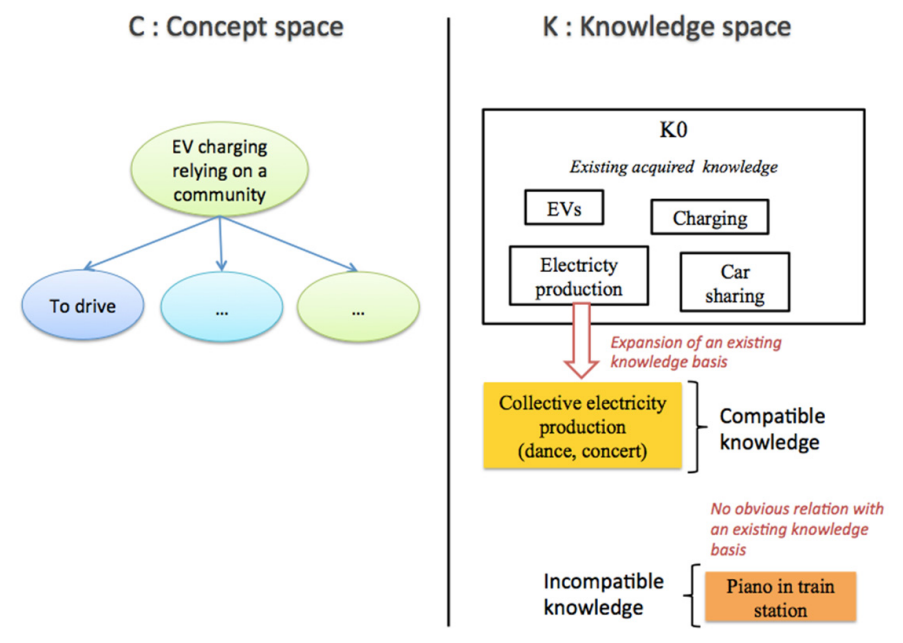

Figure 4. Examples of compatible and incompatible knowledge in Case 2 
Among the 48 pictures of the card deck, 36 pictures corresponded to compatible knowledge (e.g. knowledge on electricity production, battery technology, EV charging solutions). Among them, 5 pictures were already in K0 (they represented a charging point, an EV parking spot near a supermarket, a smart grid, an EV parking spot in a private company, and the ChargeMap application). The other pictures presented knowledge that consisted in direct expansions of $\mathrm{K} 0$ bases (e.g. a picture of a piezoelectric dancefloor, which is related to electricity production). 11 pictures corresponded to incompatible knowledge $\mathrm{K}^{*}$ (see Table 1 below). For instance, one of the pictures represented a piano made available to users in a train station: such knowledge cannot be reached by a simple expansion of $\mathrm{K} 0$ bases and constitutes incompatible knowledge. Moreover, one picture was not interpretable and was therefore removed from the sample. Whenever a picture was presented to the Renault team, either a D$>\mathrm{K}$ or a D-> K* operation occurred. In Case 2 , no $\mathrm{D}->\mathrm{C}$ or $\mathrm{C}->\mathrm{D}$ operation was observed.

Table 1. Occurrence of knowledge inputs brought by non-verbal devices in Cases 1 and 2

\begin{tabular}{|c|c|c|}
\hline \multirow{2}{*}{ Case 1 } & \multicolumn{2}{|c|}{ Numbers of D->K and D-> $\mathbf{K}^{*}$ operations } \\
\hline \multirow{2}{*}{ Case 2 } & $\mathrm{D}->\mathrm{K}$ & 7 \\
\cline { 2 - 3 } & $\mathrm{D}->\mathrm{K}^{*}$ & 6 \\
\cline { 2 - 3 } & $\mathrm{D}->\mathrm{K}$ & 36 \\
\hline & $\mathrm{D}->\mathrm{K}^{*}$ & 11 \\
\hline
\end{tabular}

Therefore, in both case studies, no operation involving both D and C was observed: in Case 1, very surprisingly the designer worked mainly in the knowledge space and chose to build his knowledge base very carefully. The architect tested some K-elements in his drawings and, depending on the result, chose to keep some elements in his knowledge basis and to remove the others. In Case 2, the absence of operation involving concepts comes from the protocol that was given to the team. Pictures were first presented to the participants, which consists in a $\mathrm{D}->\mathrm{K} / \mathrm{K}^{*}$ operation. Team members were thus asked to generate new ideas from the pictures (for instance, through a $\mathrm{K}->\mathrm{C}$ operation). In this case, the nature of knowledge represented in the pictures may also play a major role in generativity and has thus to be further investigated.

Whereas some design strategies aim at generating as many concepts as possible without focusing on new knowledge introduction and knowledge quality, our case study thus allow highlighting two design strategies related mainly to knowledge. The following section explores how new knowledge introduction helped generating new concepts in both cases.

\subsection{The impact of new knowledge inputs on knowledge restructuration and idea generation}

In Case 1, the architect strategically built his knowledge space: each K-element was carefully selected, tested and if necessary, removed from the knowledge basis. The Figure 5 presents some drawings of the architect and their impact on the knowledge space. We distinguished the initial state of the knowledge basis (K0) and simplified other knowledge bases to facilitate understanding of the architect's design process. This representation of the K-space provides only K-elements involved in the design reasoning described below, and therefore, does not aim at being exhaustive.

In the first sketch of Figure 5, the designer identifies a "Chinese motif" involving intertwining lines, which bring stability to the bookcase structure. The architect decided to work with such motif throughout his exploration (see the second and fifth sketches) and kept this new $\mathrm{K}^{*}$-input in his knowledge basis. In the third drawing of Figure 5, the designer identified a linear form that made him consider using cables ( $\mathrm{K}^{*}$-input). The architect thus tested this new knowledge in the fourth sketch of Figure 5, but looking at the drawing, he realized that cables did not allow glass integration over the entire surface of the library, which was one of the design objectives, and removed this $\mathrm{K}^{*}$ element from his knowledge basis. In Case 1, incompatible knowledge thus allows introducing originality in the knowledge basis of the architect. Sometimes, $\mathrm{K}^{*}$-elements helped introducing new 
rules in the knowledge space, which the architect found interesting and generative. This was the case for the Chinese motif: instead of working with horizontal and vertical lines that would cross, the architects begin to work with motifs that would intertwine. Knowledge on "Chinese motifs" thus change the rule of composition used by the designer. Some incompatible knowledge however were first identified as interesting alternatives by the architect, but since they did not allow to satisfy all the architect's expectations, they were removed from his K-basis. In conclusion, the design strategy of the architect was based on looking for incompatible knowledge and restructuring his own knowledge space: if this incompatible knowledge allowed breaking a rule of the previous knowledge basis, without preventing satisfying all architect's expectations, the element was used to foster generativity. However, if this incompatible knowledge did not allow satisfying the design criteria of the architect, it was removed from the K-space (the architect could not find how making this incompatible knowledge compatible).
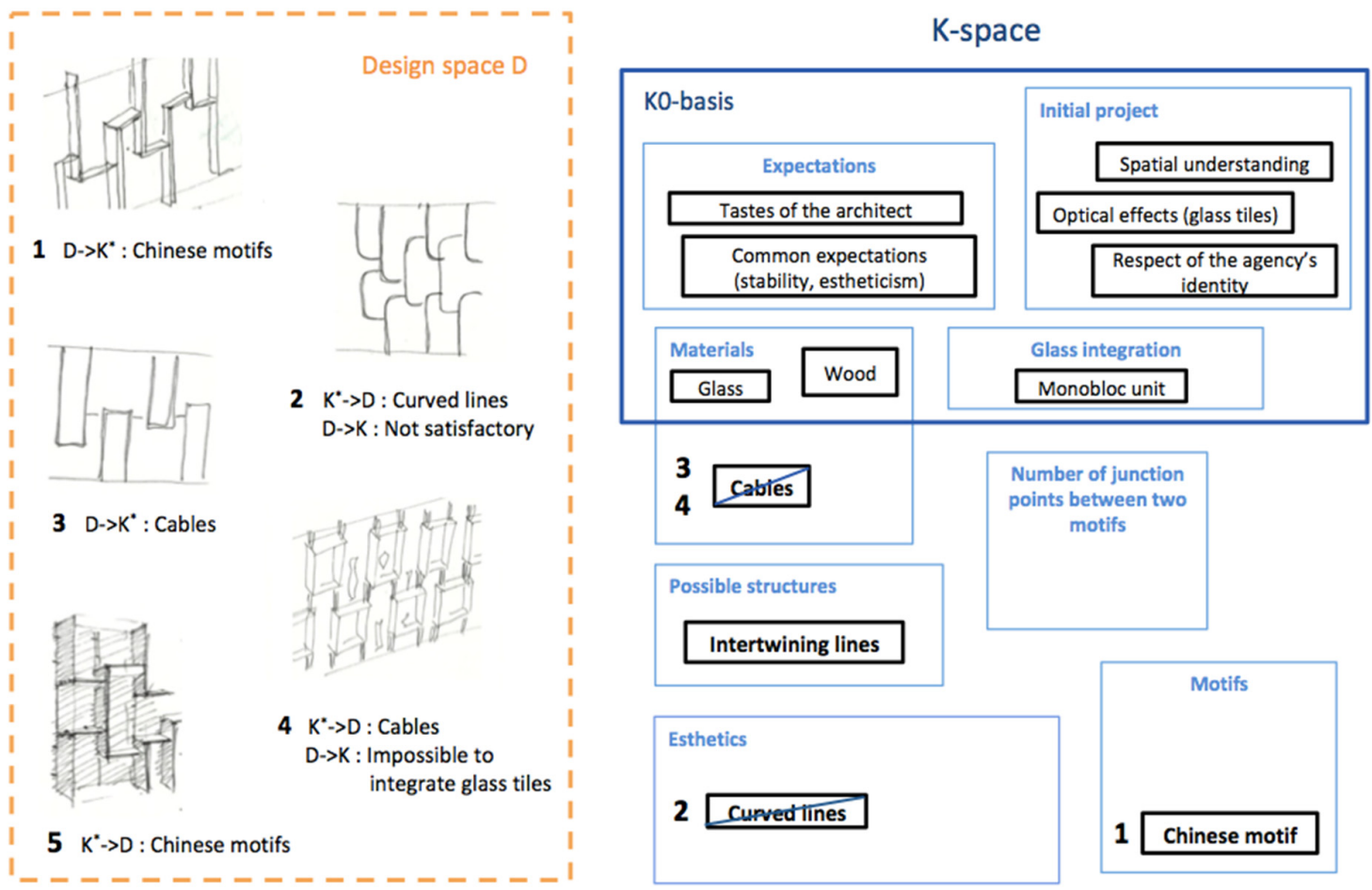

Figure 5. The impact of new knowledge inputs on the architect's design process; Left: Sketches of the "bookcase" exploration; Right: Effects of knowledge inputs on the K-space

In Case 2, during the Renault session, not every picture fostered idea generation. Especially, pictures that represented knowledge already in $\mathrm{K} 0$ did not give any idea to the team members. Other pictures allowed generating ideas through $\mathrm{D}->\mathrm{K}^{(*)}->\mathrm{C}$ operations: the pictures presented new K-elements to the participants $\left(\mathrm{D}->\mathrm{K} / \mathrm{K}^{*}\right)$, who thus used this new knowledge to generate new ideas $(\mathrm{K}->\mathrm{C})$. For instance, the picture of a piezoelectric dancefloor led to the concept of an EV charging that could bring people together (see Figure 6, left), whereas the picture representing an exchange of data between vehicles led to the concept of EVs exchanging data regarding the location and condition of charging points. Moreover, pictures representing compatible knowledge allowed generating more restrictive concepts than expansive ones ( 8 restrictive concepts, 5 expansive concepts), whereas pictures representing incompatible knowledge only led to expansive concepts (5 expansive concepts). 

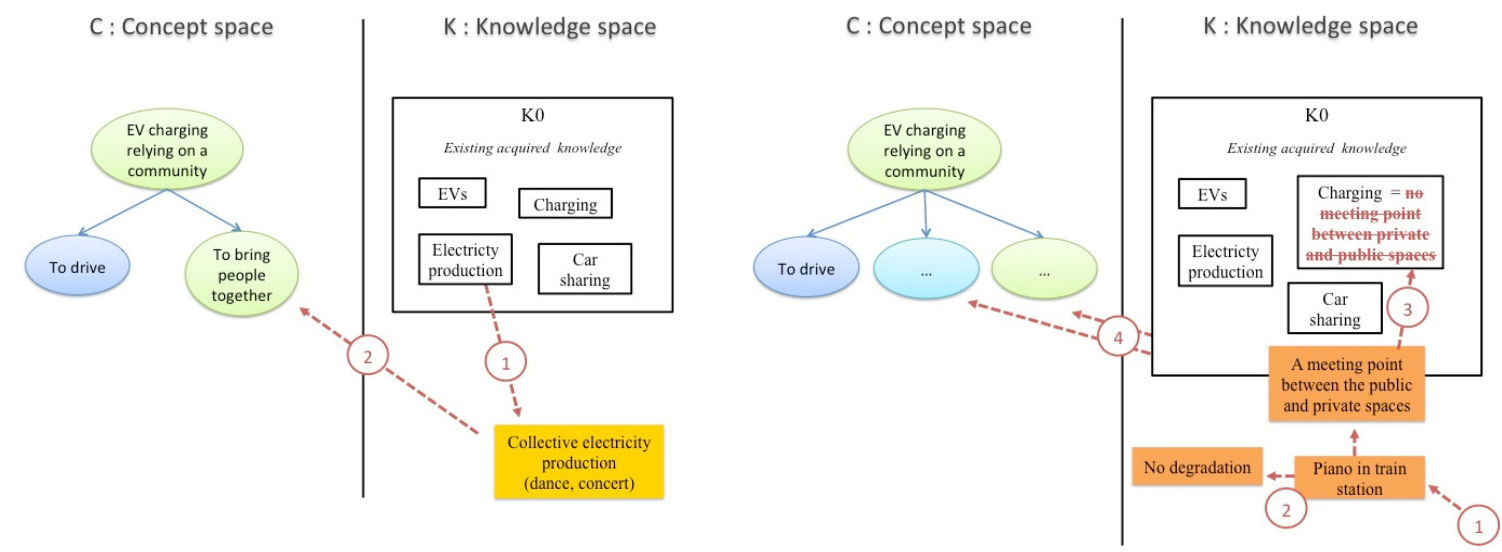

Figure 6. Concept generation mobilizing new compatible knowledge (left) and incompatible knowledge (right)

In Case 2, we observed two strategies for concept generation. The first one corresponded to classic $\mathrm{K}->\mathrm{C}$ operations: for instance, knowledge regarding models of production involving collective events - such as concerts, dance or sport - led to an expansive concept: a charging system bringing people together (Figure 6, left). In particular, knowledge on electricity production through collective events easily allowed generating concepts because it directly ensued from K0 (compatible knowledge). In this way, many compatible pictures allowed generating original concepts. It could be expected that incompatible knowledge generated original concepts following the same mechanism, but this was not observed. Some incompatible pictures did not inspire any idea because the team did not found any connection between the picture and the topic of the session: for instance, pictures presenting examples of objects' misappropriation did not allow generating new concepts. Indeed, incompatible knowledge did not impact directly the $\mathrm{C}$-space through the classic $\mathrm{K}->\mathrm{C}$ operation: they first impacted the $\mathrm{K}$ space precisely by discussing the potential links between the picture and the design topic. Since these pictures presented incompatible knowledge $\mathrm{K}^{*}$, participants had to make an effort to modify their Kspace in order to give sense to these $\mathrm{K}^{*}$-elements. Such picture thus involved a reconsideration of existing rules in the K-space. For instance, knowledge regarding train station pianos cannot be reached by a simple expansion of $\mathrm{K} 0$ bases: the piano is not an EV charging system nor a community. However, this picture was relevant regarding the design topic: pianos in train station are a success story showing a private object can be placed in public spaces without being degraded. Such knowledge thus raised the question of the frontier between the public and private spaces and showed to the team that a meeting point between the two was possible. Regarding EV charging, one of the main issue comes indeed from the fact that the private and public spaces do not meet: this statement was considered by the Renault team as both a paradigm and a constraint, but the example of the piano demonstrated that such constraint could be overcome (see Figure 6, right). Such incompatible knowledge therefore involved a knowledge reordering operation (Le Masson et al., 2013). Once the knowledge bases are reorganized, new rules governing the K-space open new conceptual paths and allow generating new types of concepts (Potier et al., 2015, Brun et al., 2016). In our case study, the picture of the piano led to the concept of a "respected" charging point (no degradation). However, additional knowledge regarding pianos in train station (maintenance, ownership, users' behavior) had to be acquired in order to know how to replicate the piano success story with an EV charging system, and imagine what such system could become in practice. Incompatible knowledge thus involves a restructuration of the initial knowledge basis $\mathrm{K} 0$ and allows generating original concepts, which follow new design rules than the ones previously governing $\mathrm{K} 0$. It is important to highlight that this ability to reorganize $\mathrm{K} 0$ does not ensue from the expansive or restrictive nature of knowledge, but from the compatibility with the structure of K0 (i.e. with existing links between K0 elements): if a knowledge input is not compatible with the initial knowledge structure, or follows different rules, restructuring knowledge will be required. This often involves expanding knowledge from both the incompatible input and K0 knowledge bases (Figure 6, right). 


\section{Discussion}

According to design theory, a new knowledge input may generate a new concept in two ways (see Figure 7): a first strategy consists in using new knowledge to directly generate a new idea, with an immediate impact on the C-space. In practice, this strategy is widely used in design methods based on C-K theory (Hatchuel and Weil, 2003, 2009). A second strategy consists in using new knowledge to reorder the knowledge space, for instance by providing a counterexample that will break a rule governing the knowledge space (Le Masson et al., 2016). In this second strategy, the new knowledge input does not directly impact the $\mathrm{C}$-space: it will first impact the $\mathrm{K}$-space, create new design rules, and allow opening new conceptual paths, which could not have been reached with the previous knowledge structure. This strategy has already been observed in research works analyzing how experienced artists taught design (Le Masson et al., 2016).

Our case study shows that design practitioners also use such strategy in their daily activities. Working on the knowledge structure may help enhancing the generativity of idea generation sessions. Moreover, our study shows that the introduction of incompatible knowledge helps provoking this generative restructuration of knowledge bases.

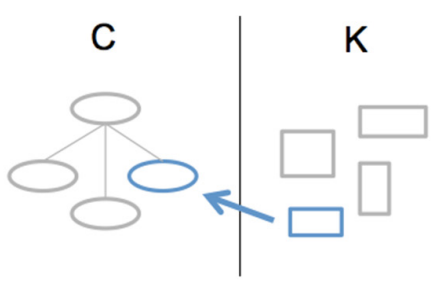

1. New $\mathrm{K}=>$ New $\mathrm{C}$

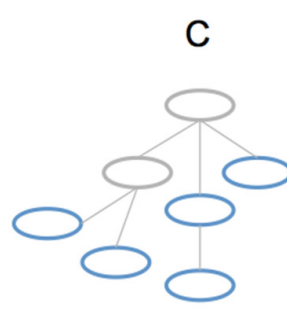

2. New $K=>$ New rules in the K-space $=>$ New concepts

Figure 7. Two strategies to generate new concepts

This study also provides some insights for design practitioners and creative leaders, who aim at enhancing their team creativity (Mueller et al., 2011): they may indeed benefit from a focus on knowledge quality instead of knowledge quantity, the latter being traditionally praised by well-known methods, such as the brainstorming process. Rather than looking for original knowledge, creative leaders may focus on incompatible knowledge in order to enhance the generation of new design rules. At last, design practitioners may support the process of knowledge restructuration by bringing additional knowledge and new directions to the team.

\section{Conclusion}

This study highlights the importance of knowledge structuration in innovative design processes. If expanding knowledge with original inputs traditionally allows reaching surprising ideas, introducing incompatible knowledge may lead to new design rules and open various disruptive paths for innovation. In order to be included in the design reasoning, incompatible knowledge will indeed require a reordering of the knowledge basis: this knowledge restructuration opens new possibilities for design and new rules of composition. If rule-based design has for long taken into account this crucial role of knowledge structuration in new product development processes, innovative design could benefit from a new type of generative effects by looking at the links and rules governing the initial knowledge basis and trying to challenge them. In the same way that the Hermès perfume designer Jean-Claude Ellena focuses on links between perfume components, innovation practitioners could benefit from a focus on the structuration of knowledge, instead of looking for knowledge quantity: indeed, in idea generation, knowledge insights do not express their full meaning independently of one another.

\section{References}

Agogué, M., Kazakçi, A., Hatchuel, A., Le Masson, P. and Weil, B. (2013), “The Impact of Type of Examples on Originality: Explaining Fixation and Stimulation Effects", The Journal of Creative Behavior, Vol. 48 No.1, pp. 1-12. https://doi.org/10.1002/jocb.37 
Brun, J., Le Masson, P. and Weil, B. (2016), "Designing with sketches: the generative effects of knowledge preordering", Design Science, Vol. 2, pp. e13. https://doi.org/10.1017/dsj.2016.13

Ellena, J.C. (2012), The Diary of a Nose: A Year in the Life of a Parfumeur, Penguin, UK.

Goel, V. (1995), Sketches of thought: MIT Press, Cambridge.

Goldschmidt, G. (2003), “The Backtalk of self-generated sketches”, Design Issues, Vol. 19 No. 1, pp. 72-88. https://doi.org/10.1162/074793603762667728

Hatchuel, A. and Weil, B. (2009), "C-K design theory: An advanced formulation”, Research in Engineering Design, Vol. 19 No. 4, pp. 181-192. https://doi.org/10.1007/s00163-008-0043-4

Hooge, S., Agogué, M. and Gillier, T. (2012), "A new methodology for advanced engineering design: Lessons from experimenting C-K Theory driven tools", Proceedings of the DESIGN 2012 / 12th International Design Conference, Dubrovnik, Croatia.

Jansson, D.G. and Smith, S.M. (1991), "Design fixation", Design Studies, Vol. 12 No. 1, pp. 3-11. https://doi.org/0142-694X/91/01003-09

Kelley, T. and Littman, J. (2001), The Art of Innovation: Lessons in Creativity from IDEO America's Leading Design Firm, Currency Doubleday, New York.

Le Masson, P., Hatchuel, A. and Weil, B. (2016), "Design theory at Bauhaus: teaching "splitting" knowledge", Research in Engineering Design, Vol. 27 No. 2, pp. 91-115. https://doi.org/10.1007/s00163-015-0206-Z

Le Masson, P., Weil, B. and Hatchuel, A. (2017), Design Theory: Methods and Organization for Innovation, Springer International Publishing, Cham.

Mueller, J.S., Goncalo, J.A. and Kamdar, D. (2011), "Recognizing creative leadership: Can creative idea expression negatively relate to perceptions of leadership potential?", Journal of Experimental Social Psychology, Vol. 47 No. 2, pp. 494-498. https://doi.org/10.1016/j.jesp.2010.11.010

Potier, O., Brun, J., Le Masson, P. and Weil, B. (2015), "How innovative design can contribute to Chemical and Process Engineering development? Opening new innovation paths by applying the C-K method", Chemical Engineering Research and Design, Vol. 103, pp. 108-122. https://doi.org/10/1016/j.cherd.2015.05.040

Reich, Y. (1995), “A critical review of general design theory”, Research in Engineering Design, Vol. 7 No. 1, pp. 1-18. https://doi.org/10.1007/BF01681909

Schön, D.A. (1983), The Reflective Practitioner: How professionals Think in Action, Basic Books, New York.

Smith, G.F. (1998), "Idea-generation techniques: A formulary of active ingredients", Journal of Creative Behavior, Vol. 32 No. 2, pp. 107-133. https://doi.org/10.1002/j.2162-6057.1998.tb00810.x

Smith, S.M., Ward, T. B. and Schumacher, J. S. (1993), "Constraining effects of examples in a creative generation task", Memory \& Cognition, Vol. 21 No. 6, pp. 837-845. https://doi.org/10.3758/BF03202751

Suh, N.P. (1990), The principles of design, Vol. 990, Oxford University press, New York.

Suh, N.P. (2001), Axiomatic design, Oxford University press, New York.

Suwa, M. and Tversky, B. (1997), "What do architects and students perceive in their design sketches? A protocol analysis”, Design Studies, Vol. 18 No. 4, pp. 385-403. https://doi.org/10.1016/S0142-694X(97)00008-2

Ulrich, K. (1995), “The Role of Product Architecture in the Manufacturing Firm”, Research Policy, Vol. 24 No. 3, pp. 419-440. https://doi.org/10.1016/0048-7333(94)00775-3

Yoshikawa, H. (1981), "General design theory and a CAD system", Man-Machine communication in CAD/CAM, Proceedings of The IFIP WG5.2-5.3 Working Conference 1980 (Tokyo), pp. 35-57.

Dr. Juliette Brun, Consultant

Earlybird, Innovation management

10 Light Street, 21202 Baltimore, United States

Email: juliett.brun@gmail.com 